\title{
Vitamin D—let common sense prevail—on the balance of probabilities
}

\author{
Helga Rhein ${ }^{1} \mathbb{0}$
}

Received: 23 June 2021 / Accepted: 13 July 2021 / Published online: 28 July 2021

(c) The Author(s), under exclusive licence to Springer Nature Switzerland AG 2021

High latitude, dark skin type, overweight, inflammatory conditions, are all predisposing factors for severe vitamin D deficiency (serum 25(OH)D below $25 \mathrm{nmol} / \mathrm{l}$ ) [1]. The authors of the latest rapid evidence review for vitamin $\mathrm{D}$ and Covid-19 [2] find the evidence not compelling enough to advise population-wide prophylactic vitamin D supplementation to prevent Covid-19 severity. They confirm, however, vitamin D's role in immune modulatory processes. Should not therefore at least those risk groups deserve to be advised on adequate vitamin $\mathrm{D}$ supplementation, better even, have their serum $25(\mathrm{OH}) \mathrm{D}$ assessed?

I disagree with the authors that existing national guidance in the UK on vitamin D supplementation appears appropriate. Firstly, this guidance is not well taken up [3], secondly, it does not abolish vitamin D deficiency, it just reduces it by a small degree [4], and thirdly, it completely ignores nutritional science by advising the same dose for all (400 IU), whether for a baby or an overweight adult.

The risk groups for vitamin D deficiency and severe Covid-19 disease are overlapping. Evidence for the benefits of avoiding D-deficiency during this pandemic far outweighs the theoretical risk of overdose. Physicians and chief medical officers should urgently and pro-actively seek to abolish vitamin D deficiency, now, ahead of a third wave, rather than only wait for further trial results.

\section{Funding None.}

This reply refers to the article available at https://doi.org/10.1007/ s40520-021-01894-z.

Helga Rhein: Retired general practitioner

Helga Rhein

helga.rhein@blueyonder.co.uk

1 Sighthill Health Centre, 380 Calder Road, Edinburgh EH11 4AU, United Kingdom

\section{Declarations}

Conflict of interest The author declares that there is no conflict of interest.

Ethical approval Not applicable.

Informed consent Not applicable.

\section{References}

1. Sutherland JP, Zhou A, Leach MJ et al (2021) Differences and determinants of vitamin D deficiency among UK biobank participants: a cross-ethnic and socioeconomic study. Clin Nutr 40:3436-3447. https://doi.org/10.1016/j.clnu.2020.11.019

2. Raisi-Estabragh Z, Martineau AR, Curtis EM et al (2021) Vitamin D and coronavirus disease 2019 (COVID-19): rapid evidence review. Aging Clin Exp Res 33:2031-2041. https://doi.org/10. 1007/s40520-021-01894-z

3. Less than one third of this Scottish population sample takes vitamin D supplements. Food Standard Agency. November 2020. https://www.foodstandards.gov.scot/downloads/Vitamin_D_resea rch_data_tables_-_for_publishing.pdf

4. Zgaga L, Theodoratou E, Farrington SM et al (2011) Diet, environmental factors, and lifestyle underlie the high prevalence of vitamin D deficiency in healthy adults in Scotland, and supplementation reduces the proportion that are severely deficient. J Nutr 141:1535-1542. https://doi.org/10.3945/jn.111.140012

Publisher's Note Springer Nature remains neutral with regard to jurisdictional claims in published maps and institutional affiliations. 